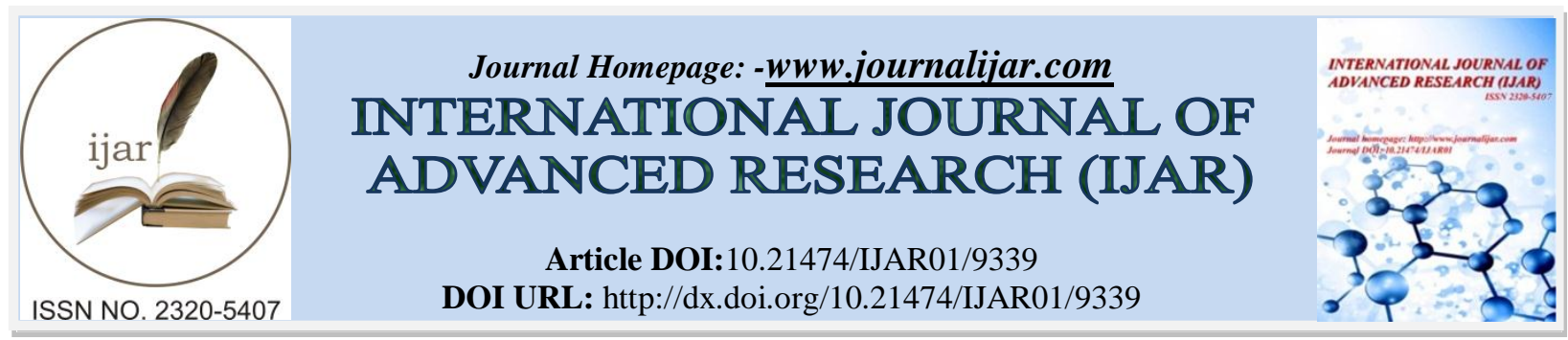

RESEARCH ARTICLE

\title{
THE EFFECT OF COACHING ON COMPETITIVE ADVANTAGE: THE MEDIATING ROLE OF HUMAN CAPITAL.
}

\section{Ines Jedidi ${ }^{1}$ and Afef Belghith ${ }^{2}$.}

1. Higher School of Economic and Commercial Sciences, Laboratory RIGUEUR, University of Tunis, Tunisia.

2. Higher Institute of Accounting and Business Administration, LaboratoryRIGUEUR, University of Manouba, Tunis, Tunisia.

\section{Manuscript Info}

Manuscript History

Received: 04 May 2019

Final Accepted: 06 June 2019

Published: July 2019

Key words:-

coaching, competitive advantage, human capital, mediator.

\begin{abstract}
The direct relationship between coaching and competitive advantage has been studied without identifying mechanisms that can explain it. Based on the resource approach, we have proposed to study the human capital as mediator in the relationship between coaching and competitive advantage. Indeed, this approach considers the intangible resources to be more highly valued than the tangible resources and the sustainable competitive advantage to be anchored in the efficient channeling of human capital. The objective of this research is to visualize the existing relationship between coaching and human capital and between human capital and competitive advantage and to infer the mediating effect of human capital in this relationship.

Our empirical study has been conducted with 127 coached managers in companies operating in the telecommunications sector in Tunisia. The results have shown that the relationship between coaching and competitive advantage is not direct and is fully mediated by the human capital.
\end{abstract}

Copy Right, IJAR, 2019,. All rights reserved.

\section{Introduction:-}

Facing an uncertain environment characterized by profound economic, social and technological changes, the company seeks to ensure its sustainability and to outperform its competitors by developing one or more competitive advantages. In order to achieve its objectives, it attaches particular importance to the employees who represent a strategic resource for the company and it uses human resources support mechanisms to improve their learning, their experience and to help them adopt the appropriate decisions. Coaching can therefore appear as an appropriate accompanying practice since it is based on a personalized relationship allowing the development of potential for a purpose of change.

By drawing on the resource approach, we have identified the following research question: To what extent can human capital play the role of mediator in the relationship between coaching and competitive advantage in telecommunication companies in Tunisia? The aim is to clarify the relationship between coaching and the human capital and between the human capital and the competitive advantage and to study the mediating effect of the human capital within this relationship.

Corresponding Author:-Ines Jedidi.

Address:-Higher School of Economic and Commercial Sciences, Tunis, University of Tunis. 
This research is structured as follows. The first part is devoted to the review of the literature from which we formulate hypotheses and develop a conceptual model. The second part presents methodology, the results of the empirical study and the discussion of the results. The last part highlights theoretical contribution and proposes perspectives for future studies.

\section{Coaching, human capital and competitive advantage: conceptualization of links Contribution of coaching on human capital}

Coaching allows a person to promote a better expression of his qualities, resources or skills. It is part of recent practices to develop human capital and to have qualified, motivated and competent staff (Moral and Henrichfreise, 2018).Indeed, coaching contributes to the updating of the managers' knowledge and skills based on learning through experience, the release of the individual's potential and the transfer of the acquired knowledge into real applications. Through coaching, the coachee has the opportunity to receive feedback and an impartial perspective from the coach. The coach helps the coachee to clarify his personal vision and objectives, to become aware of his mental patterns, and to promote positive thoughts about his skills. The coach allows him to better understand his experiences, to learn from them and to generalize them to other similar experiences (Ellinger and Kim, 2014). Coaching is similarly considered as an essential tool for developing leadership skills that builds the leader's ability to achieve short-and long-term organizational goals (Rosha, 2014). It also generates positive attitudes among the employees (satisfaction, organizational commitment, motivation) and promotes creativity. Indeed, the encouragement of free expression of feelings and emotions through coaching creates a sense of well-being of the coachee that makes him more creative. The one-to-one nature of coaching and the techniques used by the coach, such as questioning and feedback, can inspire reflection, release the mind and foster the managers' creativity (Monedi and Mouterde, 2009). The coach assists in the awakening of the coachee's creative abilities by broadening his vision, leaving him free in his choices and promoting his self-confidence, allowing him to develop his autonomy and his ability to solve problems (Hevin and Turner, 2003). Thus, we hypothesize that:

H1: Coaching has a positive effect on human capital.

\section{Contribution of human capital on competitive advantage}

The human capital is embedded in the organizational members and it is improved thanks to the learning and the individuals' experiences (Lin et al., 2016). It refers to their characteristics, knowledge, attitudes, skills, experiences and intellectual agility (Bontis, 1998). This capital has been highlighted by innumerable authors as the main source of competitive advantage (Fulmer and Ployhart, 2014). The resource approach highlights the role of the human capital in building a sustainable competitive advantage through its inimitable character based on its intangible, complex and business-specific nature (Barney, 1991). The company heavily relies on its intellectual employees who are able to create new ideas and thus foster innovation and creativity in order to obtain a competitive advantage. Every company must therefore unleash the creative potential of its employees, since the creative ideas can be used to innovate, to adapt to changing environment, and to remain competitive (Joo et al., 2013). Thus, we hypothesize that: H2: The human capital has a positive effect on competitive advantage

\section{The Effect of coaching on competitive advantage}

The competitive advantage enables the company to remain at the forefront of the current or the potential competition and to achieve superior performance ensuring a leading position. The company's human resources practices can provide a sustainable source of competitive advantage. Indeed, the way these practices influence the skills may be unique and thus inimitable given the specific systemic interactions and interdependencies accompanying it (Wright et al., 1994). Some authors believe that coaching can be a human resources management practice that allows the acquisition and the maintenance of a competitive advantage (Vidal-Salazar et al., 2012). Coaching is inspired from the field of sport and its penetration in the world of business has preserved the same spirit in terms of competition, the search for excellence and the improvement of performance. Coaching is also considered to be the indispensable tool for dealing with competition in an age when human resources are a primary source of competitive advantage (Bartlett and Ghoshal, 2002). The value of coaching also lies in its impact on the main sources of competitive advantage such as cost reduction, quality, productivity (Trenner, 2013) and innovation (Maltbia et al., 2014). Thus, we hypothesize that:

\section{H3: The coaching has a positive effect on competitive advantage}

The Mediating role of $\mathrm{HC}$ in the link between coaching and competitive advantage

The resource approach suggests that the human capital values competitive advantage because of the superior value created by its unique resources. The competitive advantage is obtained by the company seeking the best methods for 
deploying the maximum value of intangible resources (Tovstiga and Tulugurova, 2009). The literature review has shown that the human capital is an antecedent of competitive advantage and that the intangible human capital resources must be constantly updated and developed through management practices such as coaching (Wright et al., 2014). Managers must develop the necessary skills, be responsive and able to self-develop and provide innovative ideas so that they can deal with the competition (Vargas-Hernandez and Nozuri, 2010).Accordingly, we hypothesize that:

\section{H4: HC mediates the link between coaching use and competitive advantage}

\section{Research method: -}

\section{Data collection and sample}

To test the research model (Figure 1), this paper draws on a quantitative study conducted within a sample of companies operating in the telecommunication sector in Tunisia. We have chosen to test the impact of coaching among the competing companies in the telecommunications sector, which is a key sector of the Tunisian economy. The chosen target population consists of middle managers who have been coached. The data collection was based on a convenience method considering its benefits in terms of time saving and cost. In order to improve the first version of the questionnaire, we have pre-tested it using four middle managers. We have administered our questionnaire to 300 middle managers. We were only able to collect 146 questionnaires, 19 of which are unusable because they contain a lot of missing data. There are 127 available questionnaires and the response rate is $43 \%$.

All the respondents are mostly men (59.8 percent). The age of 50.4\% of the respondents is between 30 and 39 years old. $40.2 \%$ of them have an experience ranging from 5 to 10 years. $44.9 \%$ of the responses are from the company "Orange", $32.2 \%$ are from the company "Tunisie Telecom" and 22.9\% are from the company "Ooredoo".

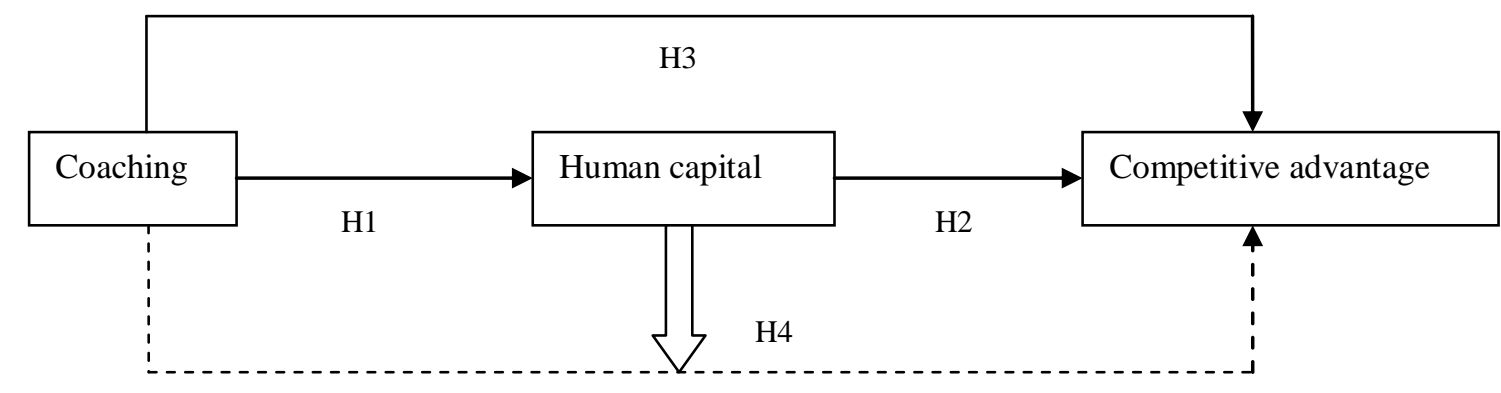

$\longrightarrow$ Direct relationship

$\ldots$ Indirect relationship

Figure 1: Conceptual model

\section{Measure}

We have used 25 items developed by Kombarakaranet al. (2008) in order to measure the dimensions of coaching, namely engagement, people management, dialogue, goal-setting and relationships with the managers. As for human capital, we have used the measurement scale conceptualized by Ramezanet al. (2011) (12 items) which describes competence, attitude and Employees' creativity. And, to measure the competitive advantage, we have used the measurement scale developed by Awwad (2011). This scale integrates five dimensions, namely, price; quality; Delivery dependability; product innovation; and time to market (14 items).

\section{Results: -}

Psychometric quality of the measurement scales

The purification of the measurement scales has been carried out in two stages. An exploratory stage using the SPSS 21 software to perform the principal component analysis (PCA) and to calculate Cronbach's alpha. We have examined the factorization conditions of each variable. The KMO index (Kaiser, Meyer and Olkin) shows values greater than 0.5 and the Bartlett test is significant for all variables. The factorization conditions are thereby verified. Subsequently, we have carried out a second PCA, with Varimax rotation. We have confirmed the multidimensionality of coaching and the uni-dimensionality of the human capital. In terms of competitive 
advantage, the resulting factor structure distributes the competitive advantage in two dimensions: "Competitive Differentiation Advantage" and "Competitive Cost Advantage" However, the two items of the "Competitive Cost Advantage" dimension are very low (because they are less than 0.3 ) and negatively correlated with the other items. In addition, this dimension has a small contribution in the total explained variance (16.966\%). For these reasons, we have chosen only the "differentiation based advantage" dimension. In short, the factor loading of all items which exceed the threshold of 0,5. The internal consistency is verified since the values of Cronbach's alphas are greater than 0.6 for all the dimensions (Table1).

Table 1: -Results of the exploratory phase

\begin{tabular}{|l|l|l|l|}
\hline Constructs & Factor loading & Cronbach's Alpha & KMO \\
\hline Coaching & $0.511-0.861$ & $0.685-0.839$ & 0.706 \\
\hline Human capital & $0.721-0.817$ & 0.946 & 0.891 \\
\hline Competitive advantage & $0.731-0.891$ & 0.905 & 0.832 \\
\hline
\end{tabular}

For the second confirmatory phase, we have mobilized LISREL 9.2 software to conduct confirmatory factor analyzes designed to verify the reliability and validity of the measuring instruments. The adjustment indices of the measurement models are satisfactory (table 2)

Table 2: -The adjustment indices of the measurement models

\begin{tabular}{|l|l|l|l|}
\hline & Coaching & Human capital & Competitive advantage \\
\hline RMSEA & 0.095 & 0.019 & 0.15 \\
\hline NFI & 0.93 & 0.94 & 0.93 \\
\hline CFI & 0.96 & 1.00 & 0.94 \\
\hline GFI & 0.93 & 0.9 & 0.9 \\
\hline CH-2 normed & 2.14 & 1.04 & 3.94 \\
\hline
\end{tabular}

The reliability has been verified for all constructs with a Jöreskog's rho above 0.6 . For the convergent validity, the rho rates are greater than 0.5 and significant at the threshold of $1 \%$ for human capital, competitive advantage and second-order coaching construction. In terms of coaching, the rho rates of convergent validity are low and express the existence of a higher order factor. Indeed, the dimensions are more correlated with each other than with their respective items (table 3 )

Given that the finally obtained factor structure is one-dimensional for the three constructs, we cannot appreciate the discriminating validity

Table 3: -Convergent Validity and Reliability

\begin{tabular}{|l|l|l|}
\hline & Jöreskog's rho & convergent validity's rho \\
\hline Coaching & 0.778 & 0.9 \\
\hline Human capital & 0.947 & 0.72 \\
\hline Competitive advantage & 0.908 & 0.59 \\
\hline
\end{tabular}

\subsection{Test of the theoretical model}

At this stage, we will verify the nature and significance of the relationships between the latent variables using the regression coefficient and Student's t test. The Student's t test must be greater than 1.96 for the relationship to be considered significant (Roussel et al., 2002). The hypothesis will therefore be confirmed or rejected. In order to verify the mediating effect, we have opted for the Baron and Kenny (1986) method.

Hypotheses $\mathrm{H} 1$ and $\mathrm{H} 2$ were confirmed (table 4). Indeed, coaching has a positive and statistically significant effect on the human capital, which is positively and significantly linked to competitive advantage. Therefore, H4 hypothesis dealing with the mediating role played by the human capital in the relationship between coaching and competitive advantage is confirmed. Hypothesis H3 concerning the direct relationship between coaching and competitive advantage is rejected. However, mediation may exist even in the absence of a significant relationship between the independent and the dependent variable (Mackinnon et al., 2007). The unconfirmed direct effect of coaching on competitive advantage remains unconfirmed when the human capital is introduced as a mediating variable $(\mathrm{t}=|1.80|<1.96)$. It is therefore a total mediation. 
Table 4: -Results of the structural model

\begin{tabular}{|l|l|l|}
\hline Structural Links & Regression Coefficient & Student's t test \\
\hline Coaching-human capital & 0.076 & $|3.40|>1.96$ \\
\hline Human capital-competitive advantage & 0.31 & $|12.88|>1.96$ \\
\hline Coaching -competitive advantage & -0.0094 & $|0.087|>1.96$ \\
\hline
\end{tabular}

\section{Discussion:-}

Our ambition in this research has been to examine the link between coaching and competitive advantage through exploring the mediating role of the human capital.

First, several studies have positively linked coaching to human capital (Silva and Cooray, 2014). Our result is in the same direction since it has enabled us to confirm a positive and significant impact of coaching on the human capital in companies belonging to the telecommunications sector in Tunisia. These companies rely on the training, the development and the support of managers. And, they similarly tend to opt for coaching as a recent practice to develop the human capital. The training plans of the 3 companies contain coaching action. Indeed, they are spending an increasing share of the training budget on this new practice. A middle manager can, through coaching, recognize and exploit his resources. He develops skills such as leadership, the ability to decode the profiles of his employees and the ability to adapt his management style to the different types of personalities.

Second, several studies have positively associated the human capital with competitive advantage, especially competitive advantage based on differentiation (Cater and Cater, 2009). Our result is in the same direction since we have found a positive and significant relationship between these two variables. Indeed, in the Tunisian context, telecommunications companies believe in the importance of the human capital and always seek to attract and retain the talents enhancing competitive advantage based on differentiation. The human capital is crucial for the success of the company in a highly competitive context. Having competent and creative employees enables a competitive advantage based on differentiation (Diaz-Fernandez et al., 2017).

Third, our results indicate that there is no positive link between coaching and competitive advantage. This could be due to the fact that the source of the competitive advantage of the telecommunications companies in Tunisia rather lies in the sophistication of the technical and commercial offer. This result may be consistent with the works of Wright et al. (2001) which states that human resource practices can be easily copied by competitors and do not follow the principles of value, scarcity, imperfect imitability and non-substitutability and therefore cannot form a basis for a sustainable competitive advantage. This result seems to contradict the researches emphasizing coaching as a management practice that enables the acquisition and maintenance of a competitive advantage (Vidal-Salazar et al., 2012).

Our study suggests that the human capital fully mediates the relationship between coaching and competitive advantage. It thus confirms the findings of Wright et al. (2014). These findings suggest that coaching enables the acquisition of competitive advantage through the human capital which constitutes a strategic resource that must be constantly updated. Indeed, coaching can contribute to the production of a specific and unique human capital for the company (Hatch and Dyer, 2004). The telecommunications companies use coaching in order to develop the skills, the positive attitudes and the creativity of the middle managers. This managers become leaders with intellectual, relational and emotional intelligence.

\section{Conclusion:-}

Despite of the importance of the coaching and the fact that firms are implementing it more and more, we do not know enough about the impact of this practice on firms. In the perspective of resource based view, the purpose of this study was to investigate the relationship between coaching and competitive advantage. To have a better understanding of these links, this research examines the mediating role of human capital that has never been explored. The Resource based view values the intangible resources more than the tangible resources and considers that the sustainable competitive advantage is anchored in the efficient channeling of human capital. The direct relationship between coaching and competitive advantage is not confirmed. This could be due to the contingencies of the Tunisian context, notably the fact that coaching is an emerging practice. Indeed, coaching is a new practice and its application is only in an initial phase and therefore cannot constitute a competitive advantage for the company. We found that coaching has only an indirect effect on competitive advantage via the mediating role of 
human capital. Indeed, this research highlights the importance of coaching in creating competitive advantage through improving the human capital. Coaching helps to develop the employees' personal and interpersonal skills and their creativity to innovate, to develop new ideas, to offer the most accessible and suitable services to customers and to create a competitive advantage based on differentiation.

This research has a number of limitations. First, the convenience sampling technique does not allow findings' generalizability. Future studies could rather perform a probabilistic sampling method. In addition, we conduct a quantitative approach that not enables understanding how concretely coaching improves human capital and competitive advantage. Future researchers may combine between qualitative and quantitative studies to focus on the dynamic relationships between variables.

\section{References:-}

1. Awwad, A.S. (2011): The influence of tactical flexibilities on the competitive advantage of a firm: an empirical study on Jordanian industrial companies: International Journal of Business and Management., 6 (1):45-60.

2. Barney, J. (1991): Firm resources and sustained competitive advantage: Journal of Management, 17(1)., 99-120.

3. Baron, R.M. and Kenny, D.A. (1986): The moderator-mediator variable distinction in social psychological research: conceptual, strategic and statistical considerations: Journal of personality and social Psychology., 51(6):1173-1182.

4. Bartlett, C.A. and Ghoshal S. (2002): Building competitive advantage through people: Sloan Management Review.,43 (2), 34-41.

5. Bontis, N. (1998): Intellectual capital: an exploratory study that develops measures and models: Management Decision., 36 (2), 63-76.

6. Cater, T. and Cater, B. (2009): Intangible resources as antecedents of a company's competitive advantage and performance: Journal for East European Management Studies., 14 (2), 186-209.

7. Diaz-Fernandez, M., Pasamar-Reyes, S. and Valle-Cabrera, R. (2017): Human capital and human resource management to achieve ambidextrous learning: a structural perspective: Business Research Quarterly., 20 (1), 63-77.

8. Ellinger, A.D. and Kim, S. (2014): Coaching and Human Resource Development: Examining Relevant Theories, Coaching Genres, and Scales to Advance Research and Practice: Advances in Developing Human Resources., 16 (2), 127-138.

9. Fulmer, I.S. and Ployhart, R.E. (2014): Our most important asset: a multidisciplinary/multilevel review of human capital valuation for research and practice: Journal of Management., 40(1), 161-192.

10. Hatch, N.W. and Dyer, J. H. (2004): Human capital and learning as a source of sustainable competitive advantage: Strategic Management Journal., 25 (12), 1155-1178.

11. Hévin, B. and Turner, J. (2003), Manuel de coaching, Dunod.

12. Joo, B., McLean, G.N.and Yang, B. (2013): Creativity and Human Resource Development: An Integrative Literature Review and a Conceptual Framework for Future Research: Human Resource Development Review., 12 (4), 390-421.

13. Kombarakaran, F.A., Yang, J.A., Baker, M.N. and Fernandes, P.B. (2008): Executive coaching, Consulting Psychology Journal: Practice and Research., 60 (1), pp78-90.

14. Lin, H.E., McDonough, E.F., Yang, J. and Wang, C. (2016): Aligning knowledge assets for exploitaton, exploration, and ambidexterity: a study of companies in high-tech parks in China: Journal of Product Innovation Management., 34 (2), 122-140.

15. Moral, M and Henrichfreise, S. (2018): Coaching d'organisation: outils et pratiques:InterEditions

16. MacKinnon, D.P., Fairchild, A.J. and Fritz, M.S. (2007): Mediation analysis: Annual Review of Psychology., 58, 593-614.

17. Maltbia, T.E., Marsick, V.J. and Ghosh, R. (2014): Executive and organizational coaching: A review of insights drawn from literature to inform HRD practice: Advances in Developing Human Resources, 16 (2), $161-183$.

18. Monédi, C. and Mouterde, S. (2009): Coacher et être coacher enentreprise: Nathan.

19. Ramezan, M. (2011): Intellectual capital and organizational organic structure in knowledge society: How are these concepts related?:International Journal of Information Management., 31, 88-95.

20. Rosha, A. (2014): Peculiarities of manifestation of coaching in organizations: Procedia- Social and Behavioral Sciences, 110, 852-860.

21. Roussel, P., Durrieu, F., Campoy, E. and El Akremi, A. (2002):Méthodesd'EquationsStructurelles:Recherche et Applications enGestion:Economica 
22. Silva, P. and Cooray, R. (2014): Building human capital in organizations through corporate social responsibility-a holistic coaching approach: Procedia-Social and Behavioral Sciences., 159, 753-758.

23. Tovstiga, G. and Tulugorova, E. (2009): Intellectual capital practices: a four-region comparative study: Journal of Intellectual Capital, 10 (1), 70-80.

24. Trenner, L. (2013): Business coaching for information professionals: Why it offers such good value for money in today's economic climate: Business Information Review., 13 (1), 27-34.

25. Vargas- Hernandez, J. and Nozuri, M. (2010): How intellectual capital and learning organization can foster organizational competitiveness?:International Journal of Business and Management., 5 (4), 183-193.

26. Vidal Salazar, M.D., FerrónVilchez, V. and CordónPozo, E. (2012): Coaching: an effective practice for business competitiveness:Competitiveness Review., 22 (5), 423-433.

27. Wright, P., Macmahan, G. and Macwilliams, A. (1994): Human resources and sustained competitive advantage: a resource-based perspective: International Journal of Human Resource Management., 5 (2), 301-326.

28. Wright, P.M., Coff, R. and Moliterno T.P. (2014): Strategic Human Capital: Crossing the Great Divide: Journal of Management, 40, (2), 353-370. 